\title{
AN APPROACH TO ECONOMIC OPTIMIZATION OF THE BATCH SIZE IN THE TEXTILE INDUSTRY
}

\author{
Sanja PUZOVIC, Miroslav RADOJICIC, Jasmina VESIC VASOVIC, \\ Vladan PAUNOVIC, Zoran NESIC
}

University of Kragujevac, Faculty of Technical Sciences Cacak, Serbia

Received: 17.10.2017

Accepted: 11.05 .2018

\begin{abstract}
One of the important factors of the economic optimization of production processes is the proper dimensioning of the batch in which production is carried out. This request becomes particularly pronounced in the conditions of the textile industry, where the economic rationalization of production is of crucial importance for a market success. In the paper, we presented the model of the optimization of the batch size based on an analysis of the structure of the expenses, inclusive of a request for their minimization. The suggested model enables the determination of the batch size which has the lowest costs and also the extent to which it is allowed to deviate from the calculated optimum, but still remain within economic rationality. The aim of the theoretical and practical aspects of the paper is to point out the contribution of the suggested approach towards the economicrationalization of production processes in the textile industry.
\end{abstract}

Keywords: Batch Size, Costs of the Series, Optimization, Production Planning, Textile Industry

Corresponding Author: Sanja Puzovic, e-mail: sanja.puzovic@ftn.kg.ac.rs / DOI: 10.32710/tekstilvekonfeksiyon.482864

\section{INTRODUCTION}

The intensification of global processes, the strengthening of competition at a global level, the market uncertainty exerting pressure on prices and the need for a quick response to the changing demands coming from consumers, the growth of economic insecurity, the accelerated pace of innovation and stricter regulations are just some of the challenges that modern business flows bring with them and which quickly change the business environment in return. These challenges are particularly pronounced in the conditions of textile production, which, with the turbulence and unpredictability of the textile market, imposes time-based competition and cost optimization as a strategic orientation of this industry (1). The struggle for competitive dominance requires not only the production of better-quality products, but also the production of products at lower prices (2). Some authors $(3,4)$ point out the fact that, in addition to environmental and social aspects, the economic aspect is crucial for the establishment of the sustainable development of the textile industry, and that the identification of the tools of economic sustainability and their implementation must be textile producers' priority. Yilmaz and Atilgan (2016) (5) indicate that the improvement of production performance is one of the important factors of creating added value in the textile industry. Ait-Alla et al. (2014) (6) also indicate that the optimization of the production costs, quality and reliability of logistics systems becomes crucial for an economic success in this industry. Under such conditions, only a strong production plan can provide maximizing profits, thus becoming crucial for the optimization of the textile industry's production processes. There are various practical and theoretical studies concerned with the development of the different models of production planning in specific textile industry conditions, aimed at optimizing production processes and overcoming the basic challenges facing the textile industry.

Rabbani et al. (2016) (7) developed a mathematical model for selecting technology for production and capacity planning in the textile industry, and the proposed model represents a mixed integer programming problem; the authors consider production planning in this industry as a make-to-order (MTO) system. Radulescu and Radulescu (2007) (8) developed a multi-objective model for production planning in the textile industry, which focuses on finding a compromise between the opposed objectives: return, financial risk and environmental risk. In his study, Elamvazuthi et al. (2009) (9) analyze the possibilities of applying the Fuzzy Linear Programming (FLP) model within the textile production planning process in the conditions of the uncertainty of parameters, whereby using the modified S-curve membership function provides a significant support to decision-making within this process. Pasayev (2010) (10) presents a production planning model for the textile industry, whose main goal is the reduction of losses in material. Karabuk (2008) (11) developed a stochastic programming approach to planning the production of yarns for different 
demand scenarios by using a two-step preprocessing algorithm. De Toni and Meneghetti (2000) (6) indicate the fact that the conditionality of the weather performance of the chain of textile firms with variables, such as the length of planning and material availability, relating to which they suggest reducing the planning period in order to optimize organizational performance.

The textile industry is characterized by stochastic, multiphased production, in which each phase has different characteristics. Some phases are characterized by a long and costly preparation, costly machines, a long planning period, whereas others are characterized by faster realization, a simpler preparation and technological processes, which all makes the production planning process more complex. The adequate dimensioning of a batch is an essential part of this process since the size of a batch largely determines the other components of the production plan: planning the material, the workforce and the machine capacity, which has a significant impact on production costs. Since the dimensioning of a batch is the key element in the organization and preparation of industrial production (12), and simultaneously an important tool for achieving an important business policy goal - minimizing costs, the choice of the models and criteria for the dimensioning of a batch represents an issue that should be addressed with particular care. The applicability of a model is conditioned by its adaptability to the specificity of production and the conditions in which it is carried out. This caused the emergence of a number of practical and theoretical studies in which the researchers' primary focus was on the consideration of the various aspects of the optimization of the volume of a batch.

The authors Rau and OuYang (2008) (13) propose a seriesoptimization model for an integrated production-inventory policy, aimed at minimizing total production costs, whereas Glock (2011) (14) focuses more on monitoring the impact of the batch size on costs, exclusively through inventory costs. Some of the studies $(15,16,17,18)$ deal with the development of different optimization models under the condition of a single-stage production system with rework options. In their study (19), Shin et al. (2009) present a stochastic model for determining the optimal size of a batch under the stochastic part-to-part variability as the function of the batch size. Omar and Smith (2002) (20) try to find an optimal model for dimensioning a batch for production systems under a linearly increasing time-varying demand process by using a dynamic program approach. Rabta and Reiner (2012) (21) suggest a model based on a combination of a genetic algorithm and the queueing network decomposition procedure. Modern studies deal with the aspects of optimization such as the study of the effect of the size of a batch on the environmental performance of machining (22). These studies are aimed at finding an optimal model that would be applicable in real production conditions, the selection of the model being conditioned by the optimization criteria which the manufacturer gives the primacy to. This paper deals with the rationalization of production from an economic point of view, not a technological one.

\section{MATERIAL AND METHOD}

The size of a batch can have a significant impact on the performance of production processes in the textile industry, especially from the economic point of view, but there are the other aspects, such as the utilization of technical capacities, the dynamics of meeting the planned delivery deadlines, the rational use of the subject matter of work, the level of inventory, etc. which should not to be neglected either. However, the optimality of the textile manufacturing process is particularly conditioned by the selection of the appropriate size of a batch since, in this industry, especially in smallscale production, the level of costs per unit of product can be sensitive even to smaller changes in the size of a batch, and, bearing in mind the fact that the basic requirement of rational business and competitive sustainability is a lower price of the cost, our basic criteria for the optimization of the number of pieces in a batch is the level of costs per unit of product. If a batch is too large, it means that the resources used will need more time to bond in production processes, and hence larger stocks (22) are generated, whereas the too-small size of a batch will condition increasing set-up costs (19), the optimization of the number of pieces in the batch will enable a decrease in the number of the stock level and the length of the production cycle, as well as the optimization of the costs of the preparation of the batch. That is the reason why it is necessary that their structure and behavior should be subjected to analysis when changing the batch size.

Batch costs $\left(c_{\text {batch }}\right)$ consist of the two components (Equation 1) that, at the product level, have different trends in changing the scope of the batch, which are fixed $(s)$ and unfixed costs $\left(c_{v}\right)$.

$$
c_{\text {batch }}=S+c_{V}
$$

The fixed costs are not related to individual products, but to the entire batch instead, and are not sensitive to the change in the volume of production, whereas a decrease in the product units has a decreasing character. This category of costs mainly refers to the costs of the technical and operational production preparation, the cost of using fixed assets, etc. In some production processes, constant costs can make a significant part of the cost of the batch, and the size of the batch has a greater impact on the level of these costs per unit of product compared to those situations where the fixed cost is lower. The unfixed costs reduced to the product have the opposite tendency of movement compared to fixed costs. If these costs form a significant part in the cost structure of the batch, then larger batch lead to higher costs per unit of product. Their amount is directly determined by the size of the batch and the constant $(a)$, calculated according to Equation (2).

$$
a=\frac{c_{m} \cdot t_{p} \cdot i}{250 \cdot 100 \cdot 60 \cdot w}
$$

where: $c_{m}$ - the costs of material per product, $i-$ the interest rate on the use of working capital (as a percentage); $t_{p}-$ the standard production time (expressed in minutes per piece);

Since the standard production time $t_{p}$ is expressed in minutes per piece, and the unit of time for the interest rate applies to one year, we use $250 \cdot 60 \cdot w$ (in Equation (2)) in order to obtain the total engagement time of the funds for one single year, where 250 stands for the average number of the workdays per year in the conditions of the Serbian 
textile industry, and $w$ is the number of the working hours per day ( 8 hours for work in one shift; 16 hours for work in two shifts; 24 hours for work in three shifts), and the value 60 is used in order to express the total engagement time of the funds in minutes.

Since the interest rate on the use of working capital is expressed in percentage, the value 100 is used in order to obtain a consistent value system.

As the growth of the batch has the opposite effect on the individual parts of the batch costs, it is necessary to apply an optimization calculation when calculating the size of the batch that will provide the lowest cost per product. The approach developed here is based on a differential basis, i.e. on determining an increase in costs for a differential increase in the volume of the batch per product according to Equations (3-4).

$$
\begin{aligned}
& n_{\text {opt }}=\frac{\partial c_{\text {batch }}}{\partial n}=\frac{\partial(S / n+a \cdot n)}{\partial n} \\
& n_{\text {opt }}=\sqrt{\frac{S}{a}}
\end{aligned}
$$

Having in mind that it is often necessary to take into account other criteria for production optimization, deviations from the calculated optimum according to the economic criterion are inevitable. Such deviations do not necessarily lead to a more drastic deviation of costs per product than a potential minimum if they are within certain limits. The limits of deviations that can be permitted depend on the share of individual cost categories in the overall cost structure of the batch. In defining these limits, it can be helpful to know the four characteristic type of cost structure of a batch that can occur in practice, each of these characteristic variants allows a different level of deviation from the optimal size of the batch.

Variant 1: This variant is characteristic for a production distinguished either by the use of expensive machines, which leads to high fixed costs, (also in the case of the use of expensive materials) or in the case of more complex products whose production time is longer, which causes a higher interest rate on the use of current assets, so the variable costs are high as well. For this type of production, batch costs are sensitive even to minor changes $( \pm 10 \%)$ in the batch volume (Figure 1).

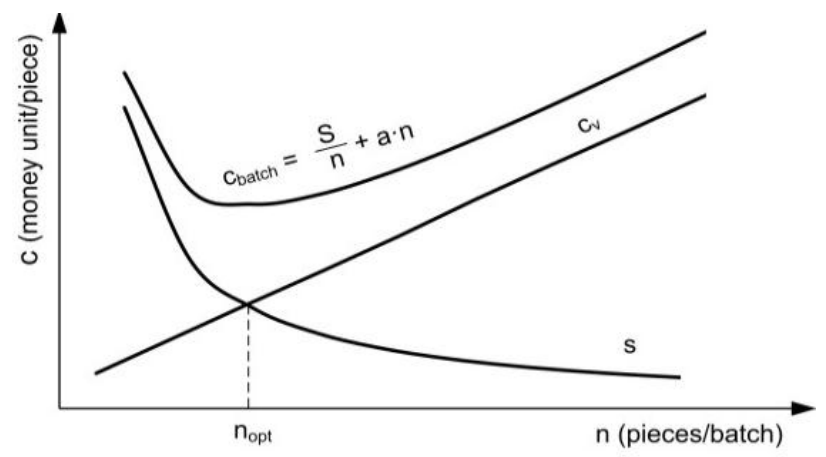

Figure 1. The first characteristic variant of the cost of the batch

Variant 2: It occurs if the preparation of the production is long and expensive, and unfixed costs are low due to the shorter process of production and the use of less expensive materials.

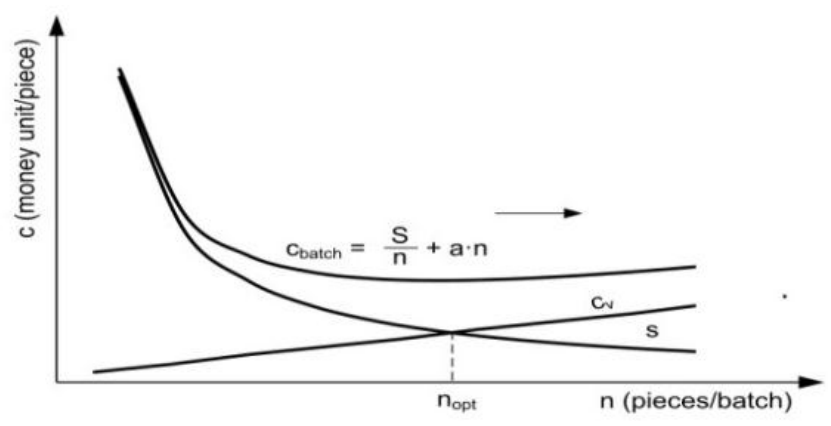

Figure 2. The second characteristic variant of the cost of the batch

Due to the high fixed costs, the carrying out of production in the batch exceeding the calculated optimum has a more favorable impact on the average costs, whereas a reduction in the batch below the calculated optimum is economically unprofitable (Figure 2)

Variant 3: Variant 3 occurs with products whose production process is long, and the materials are expensive, whereas the preparation is cheap and short. Because of lower fixed costs and high interest rates on the use of current assets, a decrease in the number of pieces in the batch a more favorable impact on costs per product compared to the calculated optimum of the increase (Figure 3 ).

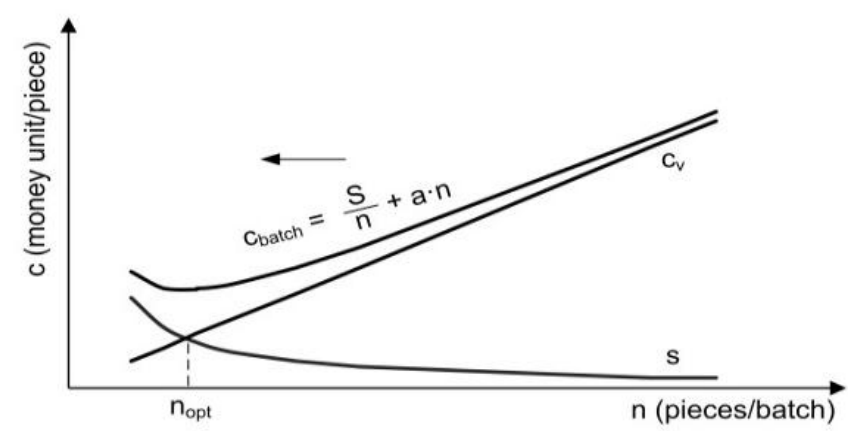

Figure 3. The third characteristic variant of the cost of the batch

Variant 4: It occurs in production with low fixed costs, the low cost of material or a shorter production time, due to which the batch costs are less sensitive to change in the number of pieces in batch (Figure 4).

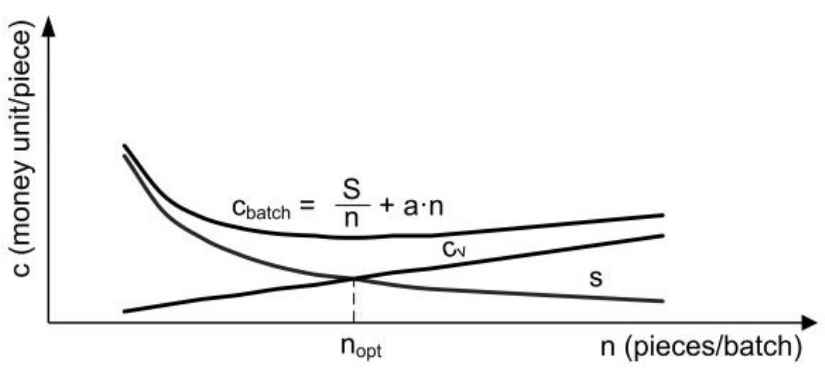

Figure 4. The fourth characteristic variant of the cost of the batch

\section{RESULTS AND DISCUSSION}

The proposed model of the budget of the economically optimal size of a batch is illustrated on the example of the 
four products of the "Stilex" company of Prijepolje, Serbia, engaged in the production of home textiles. The calculation is done for three situations: the first situation relating to the work carried out in one shift $\left(w_{1}=8\right.$ hours $)$, the second situation relating to the work done in two shifts ( $w_{2}=16$ hours) and the third relating to three-shift work $\left(w_{3}=24 h o r s\right)$. Based on the material specification and the standardized quantities, the costs of the materials necessary for the production of a product unit were also determined, whereas the standard of the production time for each single product was determined based on the technological procedures. When the interest rate on the use of current assets is concerned, the interest rate on loans for purchasing current assets, based on the conditions stipulated by the bank whose loans were used by the enterprise that was the testing ground for the case study, was applied. The cost structure was also analyzed and the characteristic type of the cost of the batch for each of the products was determined; based on that, the manner in which the deviations in the batch size from the calculated optimum could affect the unit costs and how big deviations are allowed was determined while remaining within the limits of economic cost-effectiveness. The calculation of the economically optimal size of the batch for the selected products is given below.

Product A: The production process for Product A: Padded work suit, is characterized by the longer preparation time, more expensive machines are used, and simultaneously the production time is shorter and the cost of materials is lower, which indicates that the presence of fixed costs in the structure of batch costs are higher relative to unfixed costs. The calculation is shown in Table 1 and the results are accounted for in Table 2 and Figure 5. The calculation results show that another distinctive variant of the cost is identified. Launching a smaller number of pieces than the calculated optimum of $40 \%$ leads to a cost increase per product by $13 \%$, while launching a greater number of pieces per batch by $40 \%$ leads to an increase in the average cost of only $5.7 \%$, which is indicative of the fact that the actualization of production in batch bigger than the calculated optimum conditions the lower rate of the cost increase per product unit than it is the case with the batch smaller than the specified optimum.

Also, the results (Table 2) indicate that in order to accomplish lower costs it is necessary for production to be actualized in the batch significantly smaller than those in which it is currently actualized, and if work is actualized in one shift or two shifts, the optimal size is close to the current size when the three-shift work conditions are concerned.

Product B: The production process for Product B: Bed blanket-cover 190X200 is characterized by the cheap preparation and the use of cheaper machines, the longer production time and more expensive materials, which conditions the lower presence of fixed costs relative to the unfixed. The calculation of the economically optimal batch size for the reviewed product is shown in Table 3 and the results of the calculation are accounted for in Table 4 and are graphically interpreted in Figure 6.

The results obtained show that the optimal number of pieces in the batch while working in one shift is 706.017, in two shifts 998.459, and in three shifts 1222.857 pieces; however, the company actualizes production in the batch of 5000 . The optimization of the batch size according to the shown calculation could lead to a cost decrease per product unit by $54 \%$ to $72 \%$, depending on the number of the shifts production is actualized in. In case work is actualized in one shift or two shifts, the third characteristic variant of costs appears; so, even the slightest deviation from the optimal batch size in terms of increasing the number of pieces per batch leads to a significant cost increase. In case work is actualized in three shifts, the forth characteristic variant of batch costs are present; so, the deviations from the optimal batch size do not significantly affect the cost change per product unit.

Table 1 The calculation of the economically optimal batch size for the product Padded work suit

\begin{tabular}{|c|c|c|c|c|c|c|c|c|}
\hline \multicolumn{3}{|c|}{ Batch size } & \multicolumn{2}{|c|}{1200 (pieces/batch) } & & & & \\
\hline \multicolumn{3}{|c|}{ Constant costs $(S)$} & \multicolumn{2}{|c|}{75230 (money unit) } & & & & \\
\hline \multicolumn{3}{|c|}{ Costs of materials $\left(\mathrm{c}_{\mathrm{m}}\right)$} & \multicolumn{2}{|c|}{3098.5 (money unit) } & & & & \\
\hline \multicolumn{3}{|c|}{ Production time $\left(t_{p}\right)$} & \multicolumn{2}{|c|}{$80 \mathrm{~min}$} & & & & \\
\hline \multicolumn{3}{|c|}{ Interest rate $(i)$} & \multicolumn{2}{|l|}{$9 \%$} & & & & \\
\hline \multirow[b]{2}{*}{$n \%$} & \multirow{2}{*}{$\left(\begin{array}{c}n \\
\left(\frac{\text { pieces }}{\text { batch }}\right)\end{array}\right.$} & $s$ & $c_{v 1}$ & $C_{v 2}$ & $C_{\nu 3}$ & C batch1 & $C_{\text {batch2 }}$ & $C_{\text {batch } 3}$ \\
\hline & & \multicolumn{7}{|c|}{$\frac{\text { money unit }}{\text { piece }}$} \\
\hline $10 \%$ & 120 & 626.92 & 22.31 & 11.15 & 7.44 & 649.23 & 638.07 & 634.35 \\
\hline $20 \%$ & 240 & 313.46 & 44.62 & 22.31 & 14.87 & 358.08 & 335.77 & 328.33 \\
\hline $30 \%$ & 360 & 208.97 & 66.93 & 33.46 & 22.31 & 275.90 & 242.44 & 231.28 \\
\hline $40 \%$ & 480 & 156.73 & 89.24 & 44.62 & 29.75 & 245.97 & 201.35 & 186.47 \\
\hline $50 \%$ & 600 & 125.38 & 111.55 & 55.77 & 37.18 & 236.93 & 181.16 & 162.57 \\
\hline $60 \%$ & 720 & 104.49 & 133.86 & 66.93 & 44.62 & 238.34 & 171.41 & 149.10 \\
\hline $80 \%$ & 960 & 78.36 & 178.47 & 89.24 & 59.49 & 256.84 & 167.60 & 137.86 \\
\hline $100 \%$ & 1200 & 62.69 & 223.09 & 111.55 & 74.36 & 285.78 & 174.24 & 137.06 \\
\hline
\end{tabular}

Table 2 The constant value and the optimal batch size for the Padded work suit

\begin{tabular}{|l|c|c|c|}
\hline Constant value & $a_{1}=0.18591$ & $a_{2}=0.092955$ & $a_{3}=0.06197$ \\
\hline Optimal batch size & $n_{\text {opt } 1}=636.127\left(\frac{\text { pieces }}{\text { batch }}\right)$ & $n_{\text {opt } 2}=899.62\left(\frac{\text { pieces }}{\text { batch }}\right)$ & $n_{\text {opt } 3}=1101.805\left(\frac{\text { pieces }}{\text { batch }}\right)$ \\
\hline
\end{tabular}


Table 3 The calculation of the economically optimal batch size for the product Bed blanket-cover $190 X 200$

\begin{tabular}{|c|c|c|c|c|c|c|c|c|}
\hline \multirow{2}{*}{\multicolumn{3}{|c|}{ Batch size }} & \multirow{2}{*}{\multicolumn{2}{|c|}{5000 pieces/batch }} & & & & \\
\hline & & & & & & & & \\
\hline \multicolumn{3}{|c|}{ Constant costs $(S)$} & \multicolumn{2}{|c|}{51285.25 (money unit) } & & & & \\
\hline \multicolumn{3}{|c|}{ Costs of materials $\left(c_{m}\right)$} & \multicolumn{2}{|c|}{1224.85 (money unit) } & & & & \\
\hline \multicolumn{3}{|c|}{ Production time $\left(t_{p}\right)$} & \multicolumn{2}{|c|}{$112 \mathrm{~min}$} & & & & \\
\hline \multicolumn{3}{|c|}{ Interest rate $(i)$} & \multicolumn{2}{|l|}{$9 \%$} & & & & \\
\hline \multirow[b]{2}{*}{$n \%$} & \multirow{2}{*}{$\left(\begin{array}{c}n \\
\left(\frac{\text { pieces }}{\text { batch }}\right)\end{array}\right.$} & $s$ & $C_{v 1}$ & $c_{V 2}$ & $C_{V 3}$ & Cbatch1 & Cbatch2 & Cbatch3 \\
\hline & & \multicolumn{7}{|c|}{$\frac{\text { money unit }}{\text { piece }}$} \\
\hline $10 \%$ & 500 & 102.57 & 51.44 & 25.72 & 17.15 & 154.01 & 128.29 & 119.72 \\
\hline $20 \%$ & 1000 & 51.29 & 102.89 & 51.44 & 34.30 & 154.17 & 102.73 & 85.58 \\
\hline $30 \%$ & 1500 & 34.19 & 154.33 & 77.17 & 51.44 & 188.52 & 111.36 & 85.63 \\
\hline $40 \%$ & 2000 & 25.64 & 205.77 & 102.89 & 68.59 & 231.42 & 128.53 & 94.23 \\
\hline $50 \%$ & 2500 & 20.51 & 257.22 & 128.61 & 85.74 & 277.73 & 149.12 & 106.25 \\
\hline $60 \%$ & 3000 & 17.10 & 308.66 & 154.33 & 102.89 & 325.76 & 171.43 & 119.98 \\
\hline $80 \%$ & 4000 & 12.82 & 411.55 & 205.77 & 137.18 & 424.37 & 218.60 & 150.00 \\
\hline $100 \%$ & 5000 & 10.26 & 514.44 & 257.22 & 171.48 & 524.69 & 267.48 & 181.74 \\
\hline
\end{tabular}

Table 4 The constant value and the optimal batch size for the Bed blanket-cover 190X200

\begin{tabular}{|l|c|c|c|}
\hline Constant value & $a_{1}=0.1028874$ & $a_{2}=0.0514437$ & $a_{3}=0.0342958$ \\
\hline Optimal batch size & $n_{\text {opt } 1}=706.017\left(\frac{\text { pieces }}{\text { batch }}\right)$ & $n_{\text {opt } 2}=998.459\left(\frac{\text { pieces }}{\text { batch }}\right)$ & $n_{\text {opt } 3}=1222.857\left(\frac{\text { pieces }}{\text { batch }}\right)$ \\
\hline
\end{tabular}

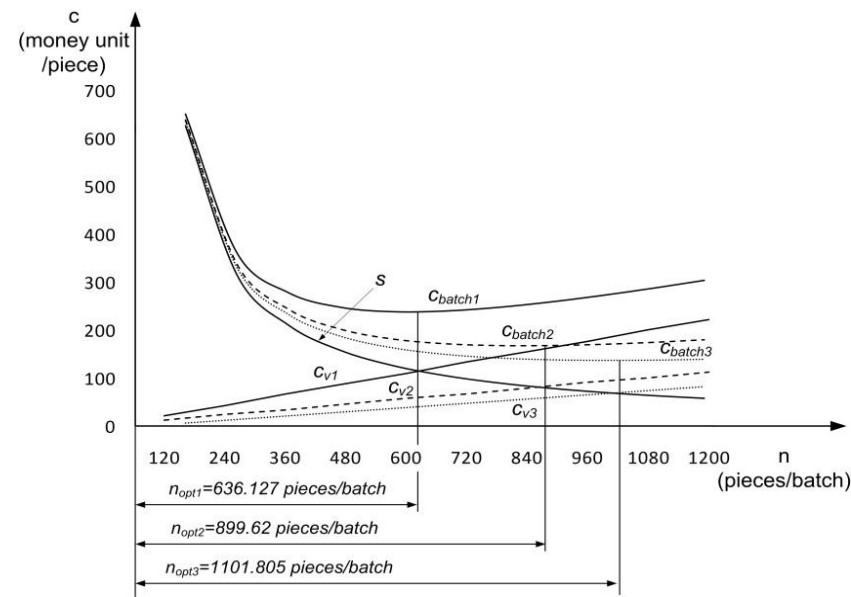

Figure 5. The optimal batch size for the product Padded work suit for work done in one shift, two and three shifts

Product C: The calculation of the optimal batch size for the product Rug $70 \times 150$ is shown in Table 5. Rug $70 \times 150$ is characterized by the short production process, the batch preparation lasts shorter, it is produced by using cheaper materials and simpler weaving machine; so, fixed and unfixed batch costs are low. The results (Table 6) show that the optimal batch size deviates by up to $70 \%$ from that used for the currently actualized production; however, as batch costs have the features of the fourth variant, the deviations from the calculated optimum do not have a significant influence on the unit cost change. The features of the fourth

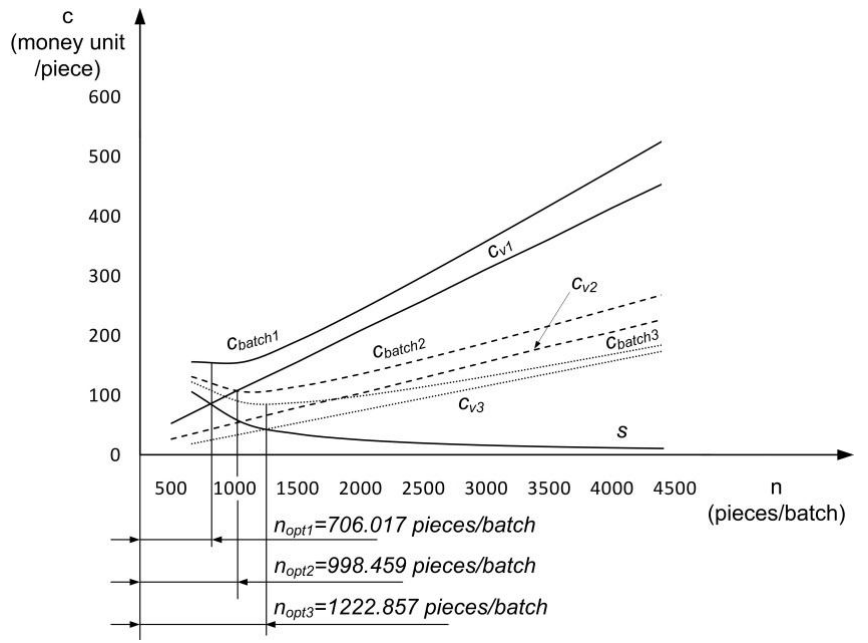

Figure 6. The optimal batch size for the product Bed blanket-cover $190 \times 200$ for work done in one shift, two and three shifts

variant of costs are the most distinctive if production is actualized in three shifts (Figure 7).

In case work is actualized in one shift, the features of the third variant of costs are more distinctive; so, if you deviate from the optimal size by increasing the number of pieces in a batch by over $20 \%$, costs per product unit increase more significantly.

Product D: Table 7 shows the calculation of the economically optimal batch size for Product D: Jogi Mattress Memory 90x200, the calculation results being shown in Table 8 and graphically interpreted in Figure 8. 
Table 5 The calculation of the economically optimal batch size for the product Rug $70 \times 150$

\begin{tabular}{|c|c|c|c|c|c|c|c|c|}
\hline \multirow{2}{*}{\multicolumn{3}{|c|}{ Batch size }} & \multirow{2}{*}{\multicolumn{2}{|c|}{6000 (pieces/batch) }} & & & & \\
\hline & & & & & & & & \\
\hline \multicolumn{3}{|c|}{ Constant costs $(S)$} & \multicolumn{2}{|c|}{22027.32 (money unit) } & & & & \\
\hline \multicolumn{3}{|c|}{ Costs of materials $\left(c_{m}\right)$} & \multicolumn{2}{|c|}{442.13 (money unit) } & & & & \\
\hline \multicolumn{3}{|c|}{ Production time $\left(t_{p}\right)$} & \multicolumn{2}{|c|}{$23 \mathrm{~min}$} & & & & \\
\hline \multicolumn{3}{|c|}{ Interest rate $(i)$} & \multicolumn{2}{|l|}{$9 \%$} & & & & \\
\hline \multirow[b]{2}{*}{$n \%$} & \multirow{2}{*}{$\left(\begin{array}{c}n \\
\left(\frac{\text { pieces }}{\text { batch }}\right)\end{array}\right.$} & $S$ & $c_{V 1}$ & $c_{v 2}$ & $c_{V 3}$ & Cbatch1 & Cbatch2 & Cbatch3 \\
\hline & & \multicolumn{7}{|c|}{$\frac{\text { moneyunit }}{\text { piece }}$} \\
\hline $10 \%$ & 600 & 36.71 & 4.58 & 2.29 & 1.53 & 41.29 & 39.00 & 38.24 \\
\hline $20 \%$ & 1200 & 18.36 & 9.15 & 4.58 & 3.05 & 27.51 & 22.93 & 21.41 \\
\hline $30 \%$ & 1800 & 12.24 & 13.73 & 6.86 & 4.58 & 25.97 & 19.10 & 16.81 \\
\hline $40 \%$ & 2400 & 9.18 & 18.30 & 9.15 & 6.10 & 27.48 & 18.33 & 15.28 \\
\hline $50 \%$ & 3000 & 7.34 & 22.88 & 11.44 & 7.63 & 30.22 & 18.78 & 14.97 \\
\hline $80 \%$ & 4800 & 4.59 & 36.61 & 18.30 & 12.20 & 41.20 & 22.89 & 16.79 \\
\hline $100 \%$ & 6000 & 3.67 & 45.76 & 22.88 & 15.25 & 49.43 & 26.55 & 18.92 \\
\hline
\end{tabular}

Table 6 The constant value and the optimal batch size for the Rug $70 \times 150$

\begin{tabular}{|l|c|c|c|}
\hline Constant value & $a_{1}=0.007626743$ & $a_{2}=0.003813371$ & $a_{3}=0.002542248$ \\
\hline Optimal batch size & $n_{\text {opt } 1}=1699.461\left(\frac{\text { pieces }}{\text { batch }}\right)$ & $n_{\text {opt } 2}=2403.401\left(\frac{\text { pieces }}{\text { batch }}\right)$ & $n_{\text {opt } 3}=2943.553\left(\frac{\text { pieces }}{\text { batch }}\right)$ \\
\hline
\end{tabular}

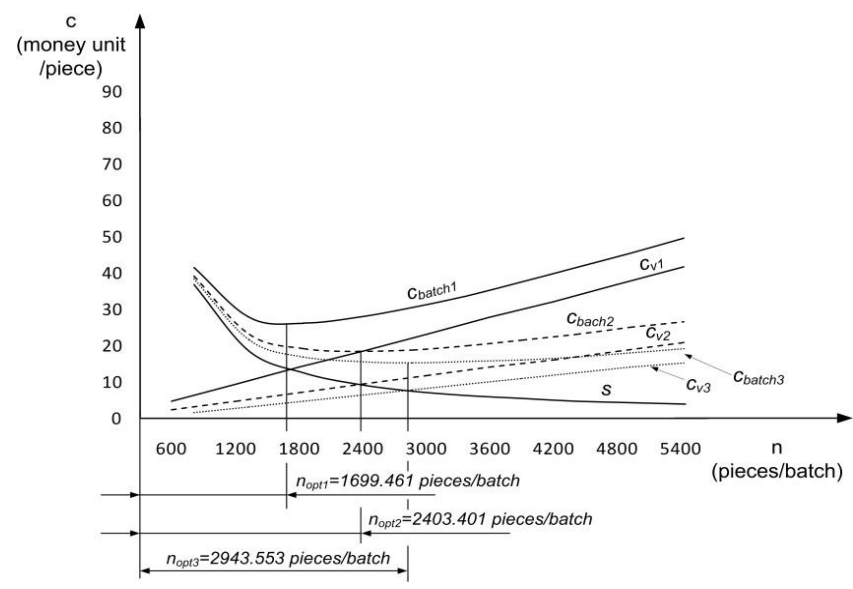

Figure 7. The optimal batch size for the product Rug $70 \times 150$ for work done in one shift, two and three shifts
The production process of Product $D$ is long and complex, the materials used for its production are expensive because of their special features, the production technology is complex and expensive, the production preparation is long; so, the fixed and unfixed costs are high, which is characteristic of the first variant of the batch costs. This is indicative of the fact that deviations from the calculated optimum can significantly affect change in the cost rate, for which reason no deviation higher than $\pm 10 \%$ is recommended. In order to optimize production in function of costs, the company should actualize production in the batch of a significantly smaller volume relative to the current situation. By decreasing the batch by $66 \%$ while working in one shift, $52 \%$ while working in two shifts, and $41 \%$ while working in three shifts, the optimal costs per product unit of product lower relative to the current ones by $40 \%, 23 \%$ or $13 \%$, depending on the number of the shifts, are obtained.

Table 7 The calculation of the economically optimal batch size for the product Jogi Mattress Memory 90x200

\begin{tabular}{|c|c|c|c|c|c|c|c|c|}
\hline \multicolumn{3}{|c|}{ Batch size } & \multicolumn{2}{|c|}{2000 (pieces/batch) } & & & & \\
\hline \multicolumn{3}{|c|}{ Constant costs $(S)$} & \multicolumn{2}{|c|}{1322362 (money unit) } & & & & \\
\hline \multicolumn{3}{|c|}{ Costs of materials $\left(c_{m}\right)$} & \multicolumn{2}{|c|}{14406.32 (money unit) } & & & & \\
\hline \multicolumn{3}{|c|}{ Production time $\left(t_{p}\right)$} & \multicolumn{2}{|c|}{$268 \mathrm{~min}$} & & & & \\
\hline \multicolumn{3}{|c|}{ Interest rate $(i)$} & \multicolumn{2}{|l|}{$9 \%$} & & & & \\
\hline \multirow[b]{2}{*}{$n \%$} & \multirow{2}{*}{$\left(\begin{array}{c}n \\
\left(\frac{\text { pieces }}{\text { batch }}\right.\end{array}\right)$} & $s$ & $C_{v 1}$ & $C_{v 2}$ & $C_{V 3}$ & Cbatch1 & Cbatch2 & Cbatch3 \\
\hline & & \multicolumn{7}{|c|}{$\frac{\text { money unit }}{\text { piece }}$} \\
\hline $10 \%$ & 200 & 6611.81 & 579.13 & 289.57 & 193.04 & 7190.94 & 6901.38 & 6804.85 \\
\hline $20 \%$ & 400 & 3305.91 & 1158.27 & 579.13 & 386.09 & 4464.17 & 3885.04 & 3691.99 \\
\hline $30 \%$ & 600 & 2203.94 & 1737.40 & 868.70 & 579.13 & 3941.34 & 3072.64 & 2783.07 \\
\hline $40 \%$ & 800 & 1652.95 & 2316.54 & 1158.27 & 772.18 & 3969.49 & 2811.22 & 2425.13 \\
\hline $50 \%$ & 1000 & 1322.36 & 2895.67 & 1447.84 & 965.22 & 4218.03 & 2770.20 & 2287.59 \\
\hline $60 \%$ & 1200 & 1101,97 & 3474,80 & 1737,40 & 1158,27 & 4576,77 & 2839.37 & 2260,24 \\
\hline $80 \%$ & 1600 & 826.48 & 4633.07 & 2316.54 & 1544.36 & 5459.55 & 3143.01 & 2370.83 \\
\hline $100 \%$ & 2000 & 661.18 & 5791.34 & 2895.67 & 1930.45 & 6452.52 & 3556.85 & 2591.63 \\
\hline
\end{tabular}


Table 8 The constant value and the optimal batch size for the Jogi Mattress Memory 90x200

\begin{tabular}{|l|c|c|c|}
\hline Constant value & $a_{1}=2.89567032$ & $a_{2}=1.44783516$ & $a_{3}=0.96522344$ \\
\hline Optimal batch size & $n_{\text {opt } 1}=675.773\left(\frac{\text { pieces }}{\text { batch }}\right)$ & $n_{\text {opt } 2}=955.687\left(\frac{\text { pieces }}{\text { batch }}\right)$ & $n_{\text {opt3 }}=1170.473\left(\frac{\text { pieces }}{\text { batch }}\right)$ \\
\hline
\end{tabular}

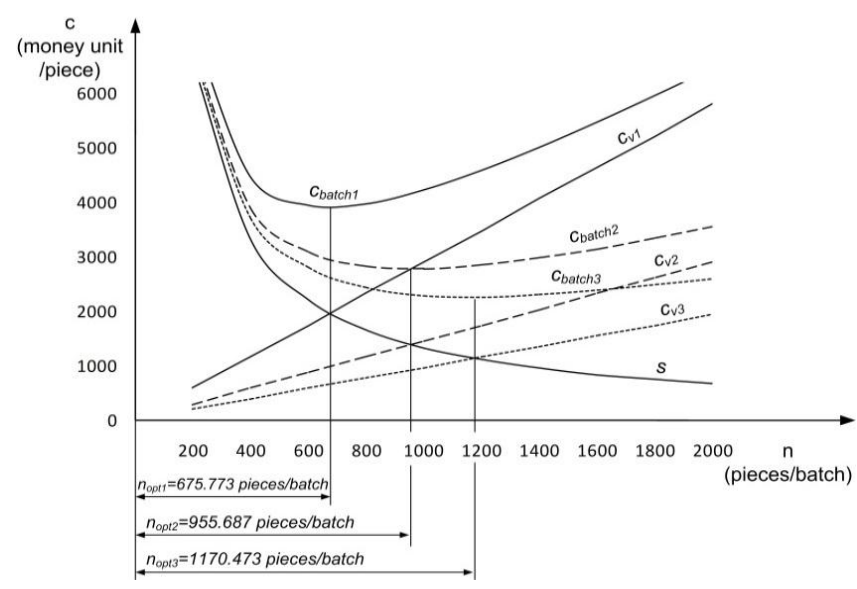

Figure 8. The optimal batch size for the product Jogi Mattress Memory $90 \times 200$ for work done in one shift, two and three shifts

\section{CONCLUSIONS}

In this paper, the significance of the batch size in industrial production conditions, i.e. the influence of the number of pieces in a batch on the cost price of the product, is put an emphasis on. The proposed model enables the efficient determination of the number of the pieces that should be launched in a certain batch so as to achieve the minimum costs per product unit. In the paper, the economically optimal batch size was calculated by using the proposed model on the examples of the four home textile products of different structures and expense rates, different production technologies and the different duriations of the production process. As the specific features of textile production and numerous organizational and technical factors lead to inevitable deviations from the optimal batch size, the proposed model enables the determination of the allowed limitations of those deviations, while still remaining within the boundaries of economic profitability. Based on the batch costs structure analysis and the laws of their movement relative to the production volume changes, the characteristic types of batch costs for each analyzed production process were identified, which served as the basis for defining further reactions in terms of the direction and intensity of allowed deviations relative to the calculated optimum. The application of this model is becoming a significant tool in production planning in the textile industry's conditions, since economical optimization of production is the key to achieving a market success in this industry.

\section{Acknowledgement}

This paper was supported by the research project No. TR35017 of the Ministry of Education, Science and Technological Development of the Republic of Serbia.

\section{REFERENCES}

1. De Toni A., and Meneghetti, A., 2000, "The production planning process for a network of firms in the textile-apparel industry", International Journal of Production Economics, Vol:65(1), pp:17-32.

2. Yönetimi T.S.T.K. and Memnuniyeti C.K.V.M., 2017, "Examining the perception of quality and customer satisfaction within the framework of total quality management in textile sector", Tekstil ve Konfeksiyon, Vol: 27(2), pp: 101-107.

3. Muthu S.S, 2017, "Sustainability in the Textile Industry" Springer Singapore.

4. Acar E., Kilic M., Güner M., 2015, "Measurement of sustainability performance in textile industry by using a multi-criteria decision making method", Tekstil ve Konfeksiyon, Vol: 25(1), pp: 3-9.

5. Yilmaz E. and Atilgan T., 2016, "Analysis of added value creation process in ready-made clothing sector: "Turkish case", Tekstil ve Konfeksiyon, Vol: 26(4), pp: 337-344.

6. Ait-Alla A., Teucke M., Lütjen M., Beheshti-Kashi S., and Karimi H.R., 2014, "Robust production planning in fashion apparel industry under demand uncertainty via conditional value at risk", Mathematical Problems in Engineering, Vol: 2014, 10 pages.

7. Rabbani M., Niyazi M., and Rafiei H., 2016, "Production, technology and capacity planning for textile industry: A case study", Uncertain Supply Chain Management, Vol: 4(4), pp: 277-286.

8. Radulescu M., and Radulescu C.Z., 2007, "A multiobjective programming model for production planning under environmental constraints", IFAC Proceedings, Vol: 40(18), pp: 771-776.

9. Elamvazuthi I., Ganesan T., Vasant P., and Webb J.F., 2009, "Application of a fuzzy programming technique to production planning in the textile industry", International Journal of Computer Science and Information Security, Vol: 6(3), pp: 238-243.

10. Pasayev N., 2010, "Investigating the effects of production planning on fabric costs in confection production", Tekstil ve Konfeksiyon, Vol: 20(3), pp: 262270.

11. Karabuk S., 2008, "Production planning under uncertainty in textile manufacturing”, Journal of the Operational Research Society, Vol: 59(4), pp: 510-520.

12. Radojičić M.,Vesić Vasović J.,Nešić Z.,2013,“Application of optimization methods in the function of improving performance of organizational systems”, Faculty of Technical Sciences Čačak.

13. Rau H., and OuYang B.C., 2008, "An optimal batch size for integrated production-inventory policy in a supply chain", European Journal of Operational Research, Vol: 185(2), pp: 619-634.

14. Glock C.H., 2011, "Batch sizing with controllable production rates in a multi-stage production system", International Journal of Production Research, Vol: 49(20), pp: 6017-6039.

15. Cárdenas-Barrón L.E., 2009, "Economic production quantity with rework process at a single-stage manufacturing system with planned backorders", Computers \& Industrial Engineering, Vol: 57(3), pp: 1105-1113. 
16. Ojha D., Sarker B.R. and Biswas P., 2007, "An optimal batch size for an imperfect production system with quality assurance and rework", International Journal of Production Research, Vol: 45(14), pp: 3191-3214.

17. Sarah M., Supadi S., Omar M., 2014, "The Optimal Manufacturing Batch Size with Rework under Time-Varying Demand Process for a Finite Time Horizon", AIP Conference Proceedings, Vol: 1605, pp: 1105-1110.

18. Musa S., Supadi S.S. and Omar M., 2014, "The optimal manufacturing batch size with rework under time-varying demand process for a finite time horizon", In AIP Conference Proceedings, Vol: 1605(1), pp: 1105-1110).

19. Shin D., Park J., Kim N. and Wysk R.A., 2009, "A stochastic model for the optimal batch size in multi-step operations with process and product variability", International Journal of Production Research, Vol: 47(14), pp: 3919-3936.

20. Omar M. and Smith D.K., 2002, "An optimal batch size for a production system under linearly increasing time-varying demand process", Computers \& Industrial Engineering, Vol:42, pp:35-42.

21. Rabta B. and Reiner G., 2012, "Batch sizes optimisation by means of queueing network decomposition and genetic algorithm", International journal of Production research, Vol: 50(10), pp: 2720-2731.

22. Ingarao G., Priarone P.C., Di Lorenzo R. and Settineri L., 2016, "A methodology for evaluating the influence of batch size and part geometry on the environmental performance of machining and forming processes", Journal of Cleaner Production, Vol: 135, pp: 1611-1622. 